\title{
Citrate-containing Alkalinizing Agent
}

National Cancer Institute

\section{Source}

National Cancer Institute. Citrate-containing Alkalinizing Agent. NCI Thesaurus. Code C29369.

A combination of sodium citrate and potassium citrate with alkalizing and antiurolithic effects. Polycitra is metabolized to bicarbonates, thereby increasing urinary pH by increasing the excretion of free bicarbonate ions. A rise in urinary $\mathrm{pH}$ increases the solubility of cystine in the urine and the ionization of uric acid to more soluble urate ion. In addition, increased urinary citrate and $\mathrm{pH}$ decreases calcium ion activity by increasing calcium complexation to dissociated anions and thus decreasing the saturation of calcium oxalate. By increasing the level of plasma bicarbonate this agent also buffers excess hydrogen ion concentration and raises blood pH, thereby reversing the clinical manifestations of acidosis. 